\section{Reply to Yu and Stout}

To the Editor-We appreciate the interest of Drs. Yu and Stout in our article. ${ }^{1}$ As they point out, it is likely that the hospital water was colonized by Legionella pneumophila, because the ice machines drew from the main water distribution system. However, it is important to note that no hospitalized patients became ill due to legionella during that time. In addition, cultures of intake water filters in the bronchoscopy suite, apart from the ice machine, were negative for legionella, as were cultures of water samples obtained from the water supply to the suite. The sole environmental sources that grew legionella on culture were the ice machine filters, for which there was no record of filter changes since the machine's installation several years previously. Other water filters in the bronchoscopy suite were not colonized, because they were changed on a regular basis. Legionella has been demonstrated in biofilms on substrates, which may, in part, explain the persistence of legionella on the old ice machine filter. ${ }^{2}$ Perhaps, in addition to cultures of hospital water samples, consistent changing of water filters should be emphasized.

Because of our pseudo-outbreak, we also acknowledge the authors' efforts to encourage proactive cultures of hospital water system samples as sentinels for legionella colonization. Certain healthcare institutions have mandated prospective routine cultures of clinical water outlets (to which patients and hospital staff may be exposed) in response to healthcareacquired Legionella infections. Proactive monitoring of hos- pital water systems may aid in avoiding the misfortune of nosocomial Legionella infections, especially during this time of intense scrutiny of healthcare systems for hospital-associated infections.

\section{ACKNOWLEDGMENTS}

Potential conflicts of interest. Both authors report no conflicts of interest relevant to this article.

Audrey N. Schuetz, MD, MPH;

Bruce S. Ribner, MD, MPH

From the Department of Pathology and Laboratory Medicine (A.N.S.) and the Division of Infectious Diseases (B.S.R.), Emory University School of Medicine, Atlanta, Georgia. (Present affiliation: Department of Pathology and Laboratory Medicine, Weill Cornell Medical Center-NewYork-Presbyterian Hospital, New York [A.N.S.].)

Address reprints request to Audrey N. Schuetz, MD, MPH, $525 \mathrm{E}$ 68th St, Rm Starr 737C, New York, NY 10065 (ans9112@med.cornell.edu). Infect Control Hosp Epidemiol 2010; 31:318

(C) 2010 by The Society for Healthcare Epidemiology of America. All rights reserved. 0899-823X/2010/3103-0020 \$15.00. DOI: $10.1086 / 651068$

\section{REF E R E N C ES}

1. Schuetz AN, Hughes RL, Howard RM, et al. Pseudo-outbreak of Legionella pneumophila serogroup 8 infection associated with a contaminated ice machine in a bronchoscopy suite. Infect Control Hosp Epidemiol 2009; 30(5):461-466.

2. Lau HY, Ashbolt NJ. The role of biofilms and protozoa in Legionella pathogenesis: implications for drinking water. J Appl Microbiol 2009; 107: 368-378. 